Quality : Jurnal Kesehatan

Volume 15, Nomor 1 Tahun 2021

pISSN : 1978-4325, eISSN : 2655-2434, DOI: 10.36082/qjk.v15i1.169

\title{
MODEL PENGEMBANGAN USAHA KESEHATAN GIGI SEKOLAH BINAAN SEBAGAI LAHAN PRAKTIK KERJA LAPANGAN
}

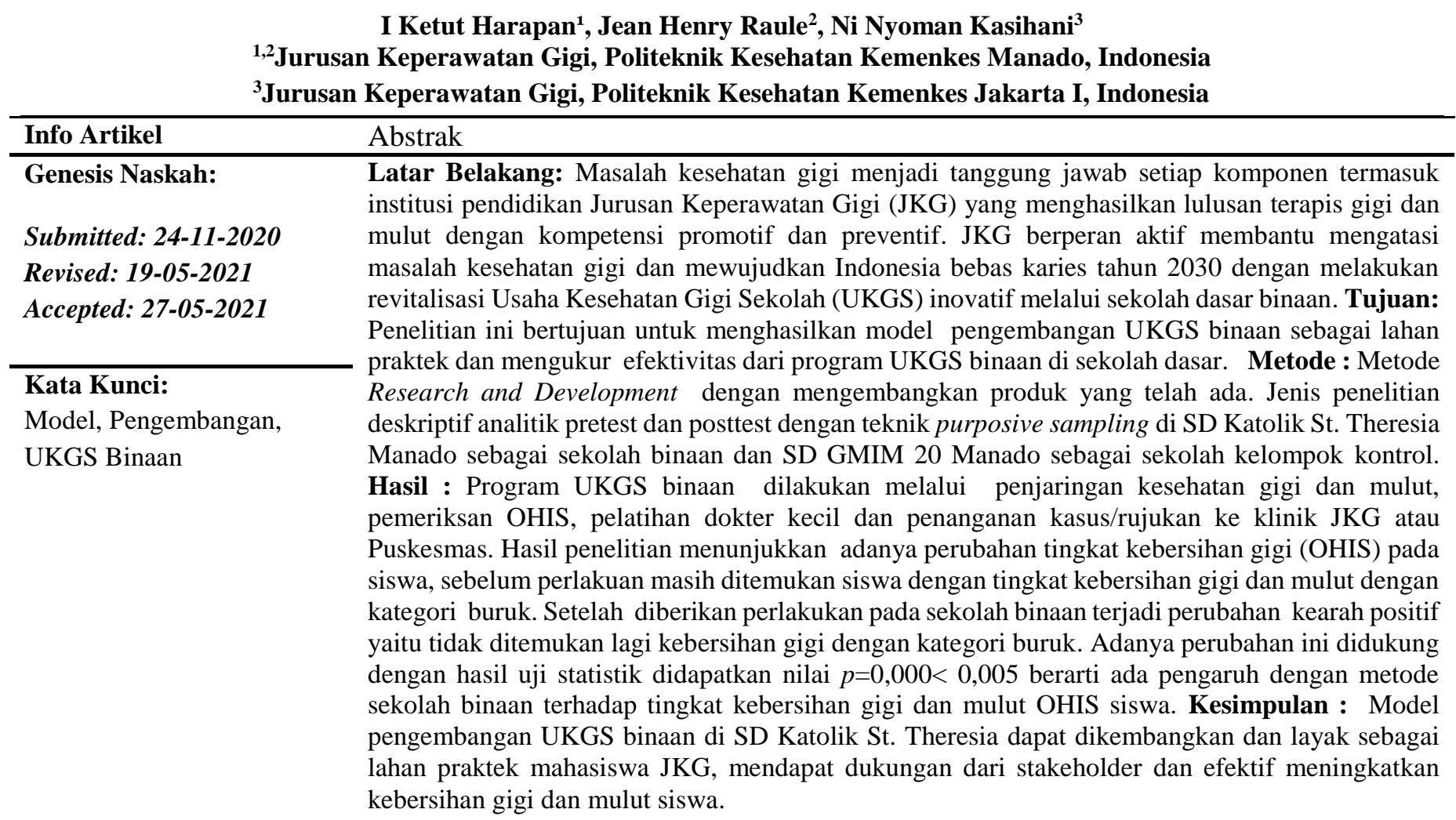

DEVELOPMENT MODEL OF SCHOOL DENTAL HEALTH SERVICE AS A FIELD WORK PRACTICE

\section{Keywords: Model,}

Development, UKGS

Assistance
Abstract
Background: Dental health issues are the responsibility of each component including the Dental
Nursing (JKG) educational institutions that produce dental and oral therapists with promotive and
preventive competencies. JKG plays an active role in helping overcome dental health problems and
realizing a caries-free Indonesia by 2030 by revitalizing innovative School Dental Health Service
(UKGS) through guided primary schools. Aim: This study aims to produce a model for developing
UKGS as a practice area and to measure the effectiveness of the UKGS program in primary
schools. Method: Research and Development method by developing existing products. This type of
research is descriptive analytic pretest and posttest with purposive sampling technique at SD
Catholic St. Theresia Manado as a target school and SD GMIM 20 Manado as a control group
school. Results: The fostered UKGS program was carried out through dental and oral health
screening, OHIS examinations, training for small doctors and case handling / referrals to the JKG
clinic or Puskesmas. The results showed that there was a change in the level of dental hygiene
(OHIS) in students, before the treatment was still found students with a bad category of dental and
oral hygiene. After being given the treatment at the target schools, there was a change in a positive
direction, namely that there was no more bad category of dental hygiene. This change was
supported by the results of statistical tests, which showed that the value of p=0.000 <0.005 means

ISSN 2655-2434
(C) Poltekkes Kemenkes Jakarta I

Jl. Wijaya Kusuma No. 47-48 Cilandak Jakarta Selatan, Indonesia

email: jurnalquality@poltekkesjakarta1.ac.id

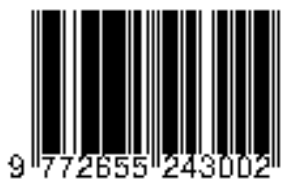


that there is an influence with the target school method on the level of OHIS dental and oral hygiene of students. Conclusion: The model for developing UKGS fostered at St. Catholic Elementary School. Theresia can be developed and is feasible as a practice area for JKG students, gets support from stakeholders and is effective in improving students' oral and dental hygiene.

\section{Korespondensi Penulis:}

I Ketut Harapan

Jl.Wolter Monginsidi, Malalayang II, Kecamatan Malalayang, Manado, Sulawesi Utara

Email: ketutharapan20@gmail.com 


\section{Pendahuluan}

Program UKGS maupun program pelayanan kesehatan gigi dan mulut yang dicanangkan pemerintah Indonesia dan dunia Internasional belum membuahkan hasil, terbukti bahwa tidak ada satu negarapun yang terbebas dari karies gigi (Kwan et al., 2005). Berdasarkan Riskesdas 2018 proporsi masalah kesehatan gigi dan mulut di Indonesia sebesar 57,6\% penduduk. Provinsi Sulawesi Utara, memiliki angka masalah kesehatan gigi dan mulut diatas rata-rata nasional diatas $60 \%$, dan angka masyarakat penerima perawatan dan pengobatan dari tenaga medis (terapis gigi dan mulut, dokter gigi atau dokter gigi spesialis) tergolong rendah hanya mencapai 12,3\% (Kemenkes, 2019).

Masalah kesehatan gigi diatas jauh dari harapan, sedangkan WHO mengharapkan Global Goals for Oral Health 2020, target Decay, Missing, FilledTeeth $(D M F-T)$ pada anak usia 12 tahun $\leq 1$. Data di atas menunjukkan masih tingginya angka kesakitan gigi dan mulut di Indonesia, diperlukan upaya-upaya dan komitmen seluruh pemangku kepentingan untuk menurunkan angka kesakitan gigi dan mulut di Indonesia serta mendukung target tahun 2030 Indonesia bebas karies (Kemenkes, 2015).

Masalah kesehatan gigi di Indonesia bukan hanya menjadi masalah pemerintah, akan tetapi menjadi tanggung jawab setiap komponen masyarakat termasuk institusi pendidikan kesehatan yang merupakan perpanjangan tangan dari Kementerian Kesehatan dalam mencetak sumber daya manusia kesehatan. Jurusan Keperawatan Gigi Manado, merupakan pelaksana teknis penyelenggara pendidikan terapis gigi dan mulut yang memiliki kompetensi promotif dan preventif kesehatan gigi. Melalui Tridharma perguruan tinggi, JKG dapat berperan aktif membantu Kementerian kesehatan dalam mengatasi masalah kesehatan gigi dan mewujudkan Indonesia bebas karies tahun 2030 dengan melakukan revitalisasi Usaha Kesehatan Gigi Sekolah (UKGS) inovatif melalui sekolah dasar binaan. Tujuan dari penelitian ini adalah membuat rancang bangun model pengembangan UKGS Binaan dan menganalisis efektifitas UKGS binaan terhadap peningkatan kesehatan dan kebersihan gigi dan mulut (OHIS) siswa sekolah dasar.

\section{Metode}

Metode yang digunakan dalam penelitian ini adalah Research and Development (R\&D). Metode R\&D

(C) Poltekkes Kemenkes Jakarta I

Jl. Wijaya Kusuma No. 47-48 Cilandak Jakarta Selatan, Indonesia email: jurnalquality@poltekkesjakarta1.ac.id merupakan salah satu proses penelitian dalam mengembangkan suatu produk baru atau menyempurnakan produk yang telah ada dan dapat dipertanggung jawabkan. Prosedur penelitian dan pengembangan meliputi 4 langkah utama antara lain: 1) pengumpulan informasi, 2) rancang bangun produk atau model, 3) validasi ahli dan revisi, 4) uji coba (Sugiyono, 2009). Jenis penelitian deskriptif analitik pretest dan posttest pemeriksaan sebelum dan sesudah perlakuan kebersihan gigi dan mulut (OHIS) siswa dengan teknik purposive sampling di SD Katolik St. Theresia Manado sebagai sekolah binaan yang diberikan perlakuan dan SD GMIM 20 Manado sebagai sekolah kelompok control. Pada kelompok control tidak diberikan perlakuan.

\section{Populasi dan Sampel Penelitian}

1. Populasi

Penelitian ini menggunakan populasi siswa salah satu Sekolah Dasar di Kota Manado berjumlah 240 anak.

2. Sampel

Sampel dalam penelitian dibagi menjadi 3 kelompok, antara lain:

a. Sampel I: sampel untuk tahap pengumpulan informasi dengan purposive sampling berjumlah 10 orang terdiri dari unsur dinas kesehatan, pihak puskesmas wilayah kerja, kepala sekolah dan guru UKS

b. Sampel II: Berjumlah 60 siswa dengan teknik purposive sampling terdiri dari 30 siswa dari SD Binaan kelas 3 dan 4 dan 30 siswa kelas 3 dan 4 pada SD pada kelompok kontrol.

\section{Prosedur Penelitian}

a. Perizinan

Sebelum Model Pengembangan Usaha Kesehatan Gigi Sekolah (UKGS) Binaan Sebagai Lahan Praktik Kerja Lapangan (PKL) dan Upaya Penyerapan Lulusan Jurusan Keperawatan Gigi Poltekkes Kemenkes Manado diimplementasikan, maka perlu melakukan perizinan.

b. Penjaringan (pre test)

Pemeriksaan gigi dilakukan untuk mengetahui keadaan kesehatan gigi pada siswa sekolah dasar.

c. Pelatihan dokter kecil

Guru dan dokter kecil diberikan pelatihan tentang Pemeliharaan kesehatan gigi di sekolah

ISSN 2655-2434 
d. Penyuluhan dan gosok gigi masal oleh dokter kecil. Dokter kecil memberikan penyuluhan tentang pemeliharaan kesehatan gigi dan mulut dan membimbing gosok gigi bersama

e. Pemeriksaan kebersihan gigi (OHIS) sesudah perlakuan (postes)

f. Bagi siswa yang memiliki masalah kesehatan gigi akan dilakukan tindakan intervensi, namun sebelumnya harus memperoleh persetujuan orang tua.

g. Analisis hasil penelitian dan di uji

h. Menyusun laporan yang ditujukan kepada Puskesmas wilayah kerja.

i. Pada tahap akhir pengumpulan informasi, data diperoleh melalui wawancara kepada Dinas Kesehatan, Dinas Pendidikan, Kepala Sekolah, Kepala Puskesmas, Guru Pembina UKGS (Guru Penjas).

\section{Hasil}

Hasil penelitian Model Pengembangan Usaha Kesehatan Gigi Sekolah (UKGS) Binaan Sebagai Lahan Praktik Kerja Lapangan (PKL) Jurusan Kesehatan Gigi Poltekkes Kemenkes Manado terbagi atas lima tahap, yakni : pengumpulan informasi, rancang bangun produk/model, validasi ahli dan revisi, uji coba produk/model, dan hasil produk/model.

\section{Deskripsi Hasil Wawancara Stacholder}

Tabel 1. Deskripsi Kesimpulan Hasil Wawancara Pengumpulan Informasi yang dilakukan pada Kepala Dinas Kesehatan, Dinas Pendidikan, Kepala Puskesmas setempat, Ketua yayasan, Kepala Sekolah, Guru UKS/penjas dan Guru wali kelas, serta 3 orang tua / wali orang tua siswa

\begin{tabular}{|c|c|}
\hline Pertanyaan & Kesimpulan \\
\hline $\begin{array}{l}\text { Bagaimana } \\
\text { program kesehatan } \\
\text { gigi dan mulut yang } \\
\text { sudah dilaksanakan } \\
\text { di sekolah dasar? }\end{array}$ & $\begin{array}{l}\text { Program kesehatan gigi dan } \\
\text { mulut pada anak sekolah dasar } \\
\text { dilakukan melalui program } \\
\text { UKGS setiap 1 tahun sekali. } \\
\text { Hal tersebut disebabkan karena } \\
\text { keterbatasan sarana, pasarana } \\
\text { dan anggaran, sehingga perlu } \\
\text { inovasi pengembangan } \\
\text { program kesehatan gigi di } \\
\text { sekolah. }\end{array}$ \\
\hline
\end{tabular}

(C) Poltekkes Kemenkes Jakarta I

Jl. Wijaya Kusuma No. 47-48 Cilandak Jakarta Selatan, Indonesia email: jurnalquality@poltekkesjakarta1.ac.id

Apa upaya dalam Upaya yang dilakukan dengan memberikan pemberian penyuluhan pendidikan mengenai kesehatan, kesehatan gigi dan pemeriksaan gigi, simulasi mulut pada anak gosok gigi, dan pelatihan sekolah dasar? dokter kecil. Agar tercipta kegiatan efektif dan efisien sebaiknya melibatkan guru dan dokter kecil.

Bagaimanakah metode UKGS yang efektif, sehingga masalah kesehatan gigi dan mulut siswa dapat diatasi?

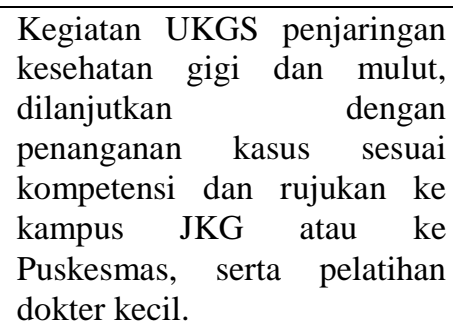
kesehatan gigi dan mulut, dilanjutkan dengan penanganan kasus sesuai kompetensi dan rujukan ke kampus JKG atau ke Puskesmas, serta pelatihan dokter kecil.

\begin{tabular}{ll}
\hline Bagaimana harapan & Ada inovasi baru untuk \\
untuk meningkatkan & merevitalisasi UKGS dengan \\
kesehatan gigi dan & melibatkan semua komponen \\
mulut? & $\begin{array}{l}\text { tenaga kesehatan, guru dan } \\
\text { siswa }\end{array}$
\end{tabular}

Hasil wawancara responden menunjukkan bahwa program kesehatan gigi dan mulut pada anak Sekolah Dasar dilakukan melalui UKGS hanya dilakukan 1 kali dalam setahun, keterbatasan sarana pasarana dan tenaga, sehingga perlu adanya inovasi pengembangan program kesehatan gigi di sekolah melalui revitalisasi UKGS.

Revitalisasi UKGS dapat dilakukan melalui upaya inovatif dengan Kegiatan UKGS penjaringan kesehatan gigi dan mulut, dilanjutkan dengan penanganan kasus sesuai kompetensi dan rujukan ke kampus JKG atau ke Puskesmas, serta pelatihan dokter kecil.

\section{Rancang Bangun Produk/Model}

Hasil pengumpulan informasi, dijadikan dasar dalam menyusun rancang bangun model pengembangan UKGS Binaan sebagai lahan praktik kerja lapangan dan upaya penyerapan lulusan Jurusan Keperawatan Gigi Poltekkes Kemenkes Manado adalah sebagai berikut. 


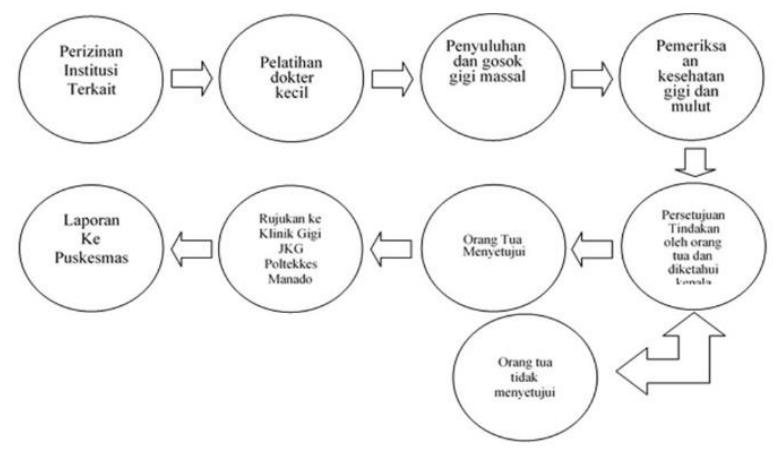

Gambar 1. Rancang bangun model pengembangan

Tahapan Rancang implementasi model Pengembangan UKGS binaan sebagai lahan Praktik Kerja Lapangan Jurusan Keperawatan Gigi Poltekkes Kemenkes Manado :

1. Perizinan

Sebelum Model Pengembangan Usaha Kesehatan Gigi Sekolah (UKGS) Binaan Sebagai Lahan Praktik Kerja Lapangan (PKL) dan Upaya Penyerapan Lulusan Jurusan Keperawatan Gigi Poltekkes Kemenkes Manado diimplementasikan, maka perlu melakukan perizinan.

2. Penjaringan

Pemeriksaan gigi dilakukan untuk mengetahui keadaan kesehatan gigi pada siswa sekolah dasar.

3. Pelatihan dokter kecil

Guru dan dokter kecil diberikan pelatihan tentang Pemeliharaan kesehatan gigi di sekolah

4. Penyuluhan dan gosok gigi massal oleh dokter kecil. Dokter kecil memberikan penyuluhan tentang pemeliharaan kesehatan gigi dan mulut dan membimbing gosok gigi bersama

5. Pemeriksaan kesehatan gigi oleh mahasiswa JKG Poltekkes Kemenkes Manado

6. Bagi siswa yang memiliki masalah kesehatan gigi akan dilakukan tindakan intervensi, namun sebelumnya harus memperoleh persetujuan orang tua.

7. Bagi siswa yang memperoleh izin dari orang tua akan diberikan rujukan ke JKG Poltekkes Kemenkes Manado untuk dilakukan intervensi

8. JKG Poltekkes Kemenkes Manado menyusun laporan yang ditujukan kepada Puskesmas wilayah kerja.

\section{Validasi hasil wawancara kepada stakeholder Hasil validasi expert sebagai berikut.}

(C) Poltekkes Kemenkes Jakarta I

Jl. Wijaya Kusuma No. 47-48 Cilandak Jakarta Selatan, Indonesia email: jurnalquality@poltekkesjakarta1.ac.id
Tabel 2. Uji Statistik Validasi Ahli model Pengembangan UKGS

\begin{tabular}{|c|c|c|c|}
\hline \multicolumn{4}{|c|}{ Validitas Ahli } \\
\hline & $\mathbf{N}$ & $\mathbf{f}(\%)$ & $\begin{array}{c}\text { p- } \\
\text { value }\end{array}$ \\
\hline Relevan & 10 & 100 & \multirow{2}{*}{0.020} \\
\hline Tidak relevan & 0 & 0 & \\
\hline $\begin{array}{r}\text { *Intra } \\
\text { Hasil va } \\
\text { p-value }=0.020 \\
\text { UKGS binaan } \\
\text { kerja lapangan } \\
\text { Kemenkes Man }\end{array}$ & $\begin{array}{l}\text { orre } \\
\text { ahli } \\
\text { art } \\
\text { seb }\end{array}$ & $\begin{array}{l}\text { efficie } \\
\text { ikkan } \mathrm{k} \\
\text { el pen } \\
\text { del lah } \\
\text { n Gigi }\end{array}$ & $\begin{array}{l}\text { nilai } \\
\text { angan } \\
\text { raktik } \\
\text { ekkes }\end{array}$ \\
\hline
\end{tabular}

3. Uji Coba Produk/Model

Uji model pengembangan UKGS binaan sebagai Lahan PKL Jurusan Keperawatan Gigi Manado untuk membentuk perilaku menggosok gigi siswa sekolah dasar menggunakan desain quasyexperimental dengan rancangan pretest and posttest control group design. Uji coba model dilaksanakan mulai bulan September 2019 sampai dengan bulan November 2019. Yang menjadi responden degan kelompok intervensi siswa SD Katolik St. Theresia pada siswa kela $\mathrm{V}$ dengan jumah 30 orang dan siswa kelas V SD GMIM 20 Manado sebagai kelompok kontrol berjumlah 30 orang. Pada kelompok komtrol tidak dilakukan intervensi.

4. Distribusi Karakteristik Responden Menurut Umur dan Jenis Kelamin Distribusi karakteristik responden berdasarkan umur dan jenis kelamin dapat dilihat pada tabel 3. dibawah ini :

Tabel.3 Distribusi karakteristik responden berdasarkan umur dan jenis kelamin

\begin{tabular}{llcc}
\hline No & $\begin{array}{c}\text { Jumlah } \\
\text { Karakteristik } \\
\text { Responden }\end{array}$ & $\begin{array}{c}\text { Persentase } \\
(\%)\end{array}$ \\
\hline 1. & Umur & & \\
\hline & $8-9$ tahun & 33 & 55 \\
& $10-11$ tahun & 27 & 45 \\
\hline 2. & Jenis Kelamin & & \\
\hline & Perempuan & 38 & 63,3 \\
& Laki - laki & 22 & 36,7 \\
\hline$\quad$ Total & $\mathbf{6 0}$ & $\mathbf{1 0 0}$ \\
\hline
\end{tabular}

Sumber : Data primer, 2019

ISSN 2655-2434 
Berdasarkan tabel 3 di atas menunjukkan bahwa persentase terbesar responden pada penelitian ini berusia 8-9 tahun sebanyak 33 orang (55\%), dan responden berjenis kelamin perempuan sebanyak 38 orang $(63.3 \%)$.

5. Distribusi frekuensi pemeriksaan OHIS awal dan akhir pada kelompok kontrol

Hasil pemeriksaan dapat dilihat pada tabel 3 dibawah ini.

Tabel 4. Distribusi frekuensi OHIS awal dan akhir kelompok kontrol

\begin{tabular}{cccc}
\hline No & Nilai OHIS & N & $\begin{array}{c}\text { Persentase } \\
(\%)\end{array}$ \\
\hline & Pretest & \\
\hline 1. & Baik & \\
\hline 2. & Sedang & 17 & 56,7 \\
\hline 3. & Buruk & 13 & 43,3 \\
\hline \multicolumn{3}{c}{ Post-test } \\
\hline 1. & Baik & \\
\hline 2. & Sedang & 12 & 40 \\
\hline 3. & Buruk & 18 & 60 \\
\hline & Total & 30 & 100 \\
\hline
\end{tabular}

Tabel 4 diatas menunjukkan bahwa pemeriksaan nilai OHIS akhir pada kelompok control tidak terjadi peningkatan, tetapi terjadi penurunan pada katagori buruk yaitu dari 13 responden menjadi 18 responden (60\%). Peningkatan OHIS dengan katagori buruk terjadi disebabkan siswa belum melakukan cara menyiat gigi secara baik dan benar.

6. Distribusi frekuensi pemeriksaan OHIS awal dan akhir pada sekolah binaan

Tabel 5. Distribusi frekuensi OHIS awal dan akhir kelompok SD UKGS binaan

\begin{tabular}{cccc}
\hline No & Nilai OHIS & N & Persentase (\%) \\
\hline \multicolumn{3}{c}{ Pretest } \\
\hline 1. & Baik & \\
\hline 2. & Sedang & 9 & 30 \\
\hline 3. & Buruk & 21 & 70 \\
\hline & Post-test & \\
\hline
\end{tabular}

(C) Poltekkes Kemenkes Jakarta I

J1. Wijaya Kusuma No. 47-48 Cilandak Jakarta Selatan, Indonesia email: jurnalquality@poltekkesjakarta1.ac.id

\begin{tabular}{cccc}
\hline 1. & Baik & 23 & 76,7 \\
\hline 2. & Sedang & 7 & 23,3 \\
\hline 3. & Buruk & & \\
\hline & Total & 30 & 100
\end{tabular}

Tebel 5 menunjukkan bahwa pemeriksaan nilai OHIS awal dan akhir pada kelompok SD binaan terjadi peningkatan nilai OHIS pada katagori baik 23 respnden $(76,7 \%)$ peningkatan terjadi karena siswa sudah memahami cara menjaga kebersihan gigi dan mulunya.

7. Tabel 6. Uji normalitas data OHIS

\begin{tabular}{ccc}
\hline \multicolumn{3}{c}{ Uji Normalitas* } \\
\hline \multirow{2}{*}{ Variabel } & \multicolumn{2}{c}{$p$-value } \\
\cline { 2 - 3 } & $\begin{array}{c}\text { Intervensi } \\
(\mathrm{n}=30)\end{array}$ & $\begin{array}{c}\text { Kontrol } \\
(\mathrm{n}=30)\end{array}$ \\
\hline Debris pre-test & 0,025 & 0,006 \\
\hline Debris post-test & 0,001 & 0,000 \\
\hline *Shapiro-Wilk & &
\end{tabular}

*Shapiro-Wilk

Hasil uji normalitas menunjukkan bahwa nilai $p$-value $<0.05$, sehingga dapat disimpulkan bahwa data berdistribusi tidak normal.

8. Analisis Pengaruh Metode Sekolah Binaan Terhadap Indeks OHI-S siswa dapat dilihat pada table 6 dibawah ini

Tabel 7. Hasil analisis Uji efektivitas OHIS murid SD pada kelompok intervensi dan kelompok kontrol

\begin{tabular}{|c|c|c|c|c|c|}
\hline \multirow[b]{2}{*}{ Kelompok } & \multicolumn{5}{|c|}{ OHIS* } \\
\hline & & \multicolumn{3}{|c|}{ Negative Sum of } & $\mathrm{Z} \pm \mathrm{p}$-value \\
\hline \multirow{2}{*}{ Intervensi } & Pre & 30 & \multirow{2}{*}{50,00} & \multirow{2}{*}{$5050,0 C$} & \multirow{2}{*}{$-8,702 \pm 0,000$} \\
\hline & Post & 30 & & & \\
\hline \multirow{2}{*}{ Kontrol } & Pre & 30 & \multirow{2}{*}{50,50} & \multirow{2}{*}{$5050,0 \mathrm{C}$} & \multirow{2}{*}{$-8,715 \pm 0,000$} \\
\hline & Post & 30 & & & \\
\hline
\end{tabular}

Hasil uji efektivitas OHIS menunjukkan bahwa nilai $p$-value $<0.05$ artinya model Pengembangan Institusi Melalui Usaha Kesehatan Gigi Sekolah (UKGS) binaan sebagai Lahan Praktik Kerja Lapangan (PKL) Jurusan Kesehatan

ISSN 2655-2434 
Gigi Poltekkes Kemenkes Manado efektif meningkatkan skor OHIS siswa sekolah dasar.

\section{Pembahasan}

Tenaga atau manusia merupakan sarana penting dan utama dalam melaksanakan suatu program guna mencapai tujuan yang telah ditetapkan. Tanpa adanya tenaga atau manusia, maka suatu program tidak dapat berjalan atau terlaksana. Berdasarkan hasil penelitian terkait tenaga pelaksana program UKGS, dapat disimpulkan bahwa tenaga pelaksana yang terlibat yaitu guru Penjaskes. Hal ini didukung dengan pendapat Astuti Febiana Mustofa (2010: 58) bahwa tugas sebagai pembina UKGS merupakan tugas tambahan namun sudah menjadi tanggung jawab dan melekat sebagai guru pendidikan jasmani dan kesehatan. Hal ini karena dimana-mana tanggung jawab sebagai guru pembina UKS maupun UKGS selalu diserahkan pada guru Penjaskes.

Tenaga atau manusia merupakan sarana penting dan utama dalam melaksanakan suatu program guna mencapai tujuan yang telah ditetapkan. Tanpa adanya tenaga atau manusia, maka suatu program tidak dapat berjalan atau terlaksana. Berdasarkan hasil penelitian terkait tenaga pelaksana program UKGS, dapat disimpulkan bahwa tenaga pelaksana yang terlibat yaitu guru Penjaskes. Hal ini didukung dengan pendapat Astuti Febiana Mustofa (2010) bahwa tugas sebagai pembina UKGS merupakan tugas tambahan namun sudah menjadi tanggung jawab dan melekat sebagai guru pendidikan jasmani dan kesehatan. Hal ini karena dimana-mana tanggung jawab sebagai guru pembina UKS maupun UKGS selalu diserahkan pada guru Penjaskes.

Keberhasilan suatu program ditentukan oleh kualitas sumber daya manusia (SDM) yang melaksanakannya. Semakin tinggi kualitas SDM yang dimiliki oleh suatu program, maka semakin tinggi pula tujuan yang akan dicapai. Begitu pula sebaliknya, apabila SDM pada suatu program memiliki kualitas yang rendah, maka tujuan yang telah ditetapkan tidak sepenuhnya dapat tercapai. Sumber daya manusia yang terampil berarti mampu

(C) Poltekkes Kemenkes Jakarta I

Jl. Wijaya Kusuma No. 47-48 Cilandak Jakarta Selatan, Indonesia email: jurnalquality@poltekkesjakarta1.ac.id melakukan tugas dan tanggung jawabnya dengan baik dan benar. Berdasarkan hasil penelitian, guru pembina UKGS adalah tenaga yang belum pernah mengikuti pelatihan. Selain itu guru pembina UKGS juga belum paham terkait perannya dalam program UKGS dan merasa belum memiliki tanggung jawab sebagai guru pembina UKGS. Sehingga menyebabkan guru tidak maksimal dalam melaksanakan perannya.

Hasil wawancara responden menunjukkan bahwa program kesehatan gigi dan mulut pada anak sekolah dasar dilakukan melalui UKGS hanya dilakukan 1 kali dalam setahun. Hal ini sesuai dengan hasil Riset Kesehatan Dasar Tahun 2013 bahwa Puskesmas hanya melakukan penyuluhan, penjaringan, dan bertindak sesuai kebutuhan satu kali dalam satu tahun di setiap sekolah (Kemenkes, 2013). Keterbatasan sarana prasarana dan tenaga, sehingga perlu adanya inovasi pengembangan program kesehatan gigi di sekolah melalui revitalisasi UKGS. Dalam pelaksanaan UKGS inovatif tentunya didukung dengan pendanaan yang memadai agar tujuan meningkatkan kesehatan gigi dan mulut siswa dapat tercapai. Sumber dana untuk program UKGS mempunyai peranan yang sangat penting dalam melaksanakan program UKGS, dana bisa didapatkan dari Bantuan Operasional Sekolah dan Bantuan Operasional Kesehatan. Dana tersebut digunakan untuk pengadaan perlengkapan ruang kesehatan yang diperlukan untuk menunjang kegiatan UKGS. Dana lain juga bisa di dapat dari bantuan orang tua siswa yang digunakan untuk pelatihan para tenaga pelaksana program UKGS dan latihan menggosok gigi (Kementerian Kesehatan, 2012). Berdasarkan hasil penelitian, sumber dana program UKGS di SD Katolik St. Theresia Manado berasal dari dana pemerintah berupa dana BOS (Bantuan Operasional Sekolah) dan dana dari yayasan yang digunakan untuk pengadaan perlengkapan ruang kesehatan dan berobat masalah gigi. Hal ini didukung dengan pendapat Nur Amaniah (2009), yang menyatakan bahwa biaya operasional juga diperlukan untuk mendukung pelaksanaan program UKGS sehingga tenaga pelaksana dapat menyelenggarakan dan atau memanfaatkan pelayanan kesehatan yang bertujuan untuk memelihara dan meningkatan kesehatan gigi siswa.

\section{ISSN 2655-2434}

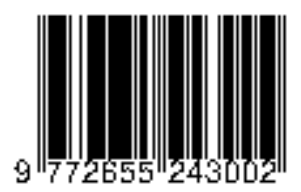


Sumber dana kegiatan UKGS berupa dana BOK (Bantuan Operasional Kesehatan) dikelola oleh Puskesmas dan digunakan untuk kegiatan pelatihan. Hasil penelitian ini berbeda dengan Nur Amaniah (2009) bahwa tidak satupun baik Puskesmas yang ada atau tidak ada dokter gigi yang memperoleh dana pelaksanaan kegiatan UKGS dari pemerintah. Hasil penelitian ini juga berbeda dengan Ida Sophia terkait biaya operasional (2008) bahwa Puskesmas tidak mempunyai biaya operasional, karena Dinas Kesehatan memenuhi kebutuhan Puskesmas seperti obat-obatan sesuai dengan jumlah kunjungan pasien Puskesmas dan memberikan dana untuk biaya operasional kegiatan UKGS seperti biaya pelatihan untuk dokter kecil.

Ketersediaan sarana dan prasarana untuk kegiatan UKGS merupakan segala jenis peralatan, perlengkapan dan fasilitas yang berfungsi sebagai alat utama dalam pelaksanaan suatu program sedangkan prasarana adalah suatu tempat atau ruangan untuk melaksanakan program. Dengan demikian bahwa sarana dan prasarana merupakan seperangkat alat yang digunakan dalam suatu proses kegiatan baik peralatan pembantu maupun peralatan utama, yang keduanya berfungsi untuk mewujudkan tujuan yang hendak dicapai. Melakukan suatu kegiatan, manusia membutuhkan sarana dan prasarana untuk mencapai tujuan yang telah ditetapkan. Tanpa ketersediaan sarana dan prasarana, suatu kegiatan tidak dapat diselesaikan sebagaimana seharusnya, bahkan akan mengalami hambatan atau tidak berjalan dengan lancar. Sarana dan prasarana merupakan seperangkat alat yang digunakan dalam suatu proses kegiatan. Sarana dan prasarana memegang peranan penting dalam pelaksanaan program UKGS. Hasil penelitian menunjukkanbahwa sarana dana prasarana di SD Katolik St. Theresia Manado belum memadai, seperti ruangan yang sangat UKS, buku pedoman UKGS dan sarana lainnya. Hal ini membuat pelaksanaan kegiatan UKGS di sekolah belum berjalan optimal seperti penyuluhan kesehatan gigi tidak dilaksanakan setiap bulan oleh guru Penjaskes karena buku pedoman tidak ada. Hal ini karena buku pedoman merupakan prasarana yang penting dan dijadikan panduan dalam melaksanakan program UKGS. Jika buku pedoman tidak ada, pelaksanaan program dapat tidak sesuai dengan yang ada dipedoman UKGS. Selain itu sarana dan prasarana (C) Poltekkes Kemenkes Jakarta I

J1. Wijaya Kusuma No. 47-48 Cilandak Jakarta Selatan, Indonesia email: jurnalquality@ poltekkesjakarta1.ac.id merupakan alat penunjang keberhasilan suatu proses dalam pelaksanaan program, karena apabila kedua hal ini tidak tersedia maka semua kegiatan yang dilakukan tidak dapat mencapai hasil yang diharapkan.

Hasil penelitian menunjukkan bahwa adanya perubahan tingkat kebersihan gigi (OHIS) pada siswa, dimana untuk sebelum perlakuan masih ditemukan siswa dengan tingkat kebersihan gigi dan mulut dengan katagori buruk. Setelah diberikan perlakukan pada sekolah binaan terjadi perubahan sebaliknya kearah positif yaitu tidak ditemukan lagi kebersihan gigi dengan kategori buruk, tetapi terjadi perubahan ke kategori baik dari yang sebelum perlakuan. Adanya perubahan ini didukung dengan hasil uji statistik pada tabel 7 didapatkan nilai $p=0,000<0,005$ berarti ada pengaruh dengan metode sekolah binaan terhadap tingkat kebersihan gigi dan mulut OHIS siswa.

Pelaksanaan kegiatan UKGS di sekolah binaan SD Katolik St. Theresia Manado perlu di tingkatkan dan dilaksanakan dengan efektif, serta di dukung dengan sarana dan prasaran serta dana yang memadai. Program ini mendapat dukungan dari pihak pengambil kebijakan agar dapat dilaksanakan secara terus menerus dan berkesinambungan, sehingga siswa sekolah memiliki kesehatan gigi yang baik.

Melaksanakan program UKGS, dibutuhkan metode agar kegiatan UKGS lebih efektif dan efisien untuk mencapai tujuan yang telah ditetapkan. Metode pelaksanaan UKGS dapat berupa UKGS tahap 1, UKGS tahap 2 dan UKGS tahap 3. Kegiatan pelayanan kesehatan dalam program UKGS meliputi pemeriksaan dan penjaringan kesehatan gigi dan mulut peserta didik, perawatan kesehatan gigi dan mulut serta rujukan kesehatan gigi mulut (Kemenkes, 2012).

Hasil pelaksanaan kegiatan UKGS harus dilakukan evaluasi secara berkala. Empat pihak yang berkewajiban untuk melakukan monitoring terkait data capaian hasil UKGS adalah Kementerian Kesehatan, Dinas Kesehatan Provinsi, Dinas Kesehatan dan Puskesmas sesuai dengan cakupan wilayahnya masing-masing (Santoso B., Triwiyatini, Gejir N., 2017). Evaluasi diperlukan ISSN 2655-2434 
untuk segera melakukan perbaikan untuk mengatasi hambatan yang ditemukan di lapangan dan dapat diupayakan terobosan atau inovasi baru agar derajat kesehatan gigi pada anak sekolah dapat ditingkatkan.

\section{Kesimpulan}

Berdasarkan hasil penelitian dapat disimpulkan bahwa model pengembangan UKGS binaan di SD Katolik St. Theresia dapat meningkatkan kebersihan gigi dan mulut (OHIS) siswa sekolah, serta mendapatkan dukungan dari pihak pengambil kebijakan/ stakholder pemerintah setempat. Sehingga model pengembangan UKGS binaan dapat dikembangkan dan layak sebagai lahan pelaksanaan praktek PKL mahasiswa Jurusan Kesehatan Gigi Poltekkes Manado.

\section{Saran :}

1. Pihak Sekolah, dapat menyiapkan sarana dan prasaran serta dana untuk menunjang program UKGS binaan.

2. Pihak Puskesmas, sebagai wilayah kerja sekolah yang menjadi program UKGS bekerja sama menyiapkan kebutuhan serta panduan kegiatan UKGS.

3. Pihak Institusi, Poltekkes Kemenkes Manado menyiapkan kerjasama (MoU) menjalin kerjasama dengan pihak Yayasan sebagai payung hukum untuk pelaksanaan UKGS binaan sebagai lahan praktek PKL mahasiswa Jurusan Kesehatan Gigi.

\section{DAFTAR PUSTAKA}

Annisa, A. (2013). Perbedaan Pengaruh Pedidikan Kesehatan Gigi Dalam Meningkatkan Pengetahuan Tentang Kesehatan Gigi Pada Anak Di Sd Negeri 2 Sambi Kecamatan Sambi Kabupaten Boyolali. Journal of Chemical Information and Modeling, 53(9), 1689-1699. https://doi.org/10.1017/CBO9781107415324. 004

Hobdell, M., Petersen, P. E., Clarkson, J., \& Johnson, N. (2003). Global goals for oral health 2020. International Dental Journal, 53(5), 285-288. https://doi.org/10.1111/j.1875595X.2003.tb00761.x

(C) Poltekkes Kemenkes Jakarta I Jl. Wijaya Kusuma No. 47-48 Cilandak Jakarta Selatan, Indonesia email: jurnalquality@ poltekkesjakarta1.ac.id
Kemendikbud. (2013). Kompetensi Dasar Sekolah Dasar dan Madrasah Ibtidaiyah. Badan Penelitian dan Pengembangan.

Kemenkes. (2012). Pedoman Usaha Kesehatan Gigi Sekolah (UKGS). Kementerian Kesehatan.

Kemenkes. (2013). Riset Kesehatan Dasar (Riskesdas) Tahun 2013. Badan Penelitian dan Pengembangan Kesehatan.

Kemenkes. (2015). Rencana Aksi Nasional Kesehatan Gigi dan Mulut Tahun 2015-2019. Kementerian Kesehatan.

Kemenkes. (2019). Laporan Nasional Riskesdas 2018. Badan Penelitian dan Pengembangan Kesehatan.

Kwan, S. Y. L., Petersen, P. E., Pine, C. M., \& Borutta, A. (2005). Health-promoting schools: An opportunity for oral health promotion. Bulletin of the World Health Organization, 83(9), 677-685. https://doi.org//S004296862005000900013

Mahon, J. F. (2001). The Effect of a Dental Health Education Program on The Dental Knowledge of Inner City and Non Inner City Elementary Age Children. Texas Woman's University.

Santoso B., Triwiyatini, Gejir N., F. D. (2017). Information System Monitoring Model Implemented in School Health Dental Unit. ARC Journal of Dental Science, 2(4), 8-11. https://doi.org/http://dx.doi.org/10.20431/245 6-0030.0204003

Shaluhiyah, Z., Nugraha, P., Tanjungkarang, P. K., Promosi, M., Universitas, K., Semarang, D., Fakultas, D., Masyarakat, K., \& Diponegoro, U. (2016). Perilaku Menggosok Gigi pada Siswa Sekolah Dasar Kelas V dan VI di Kecamatan Sumberejo. Jurnal Promosi Kesehatan Indonesia, 9(2), 127-135. https://doi.org/10.14710/jpki.9.2.127-135

Sugiyono. (2009). Metode Penelitian Kuantitatif, Kualitatif dan $R \& D$. Alfabeta.
ISSN 2655-2434

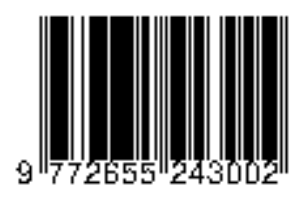

